\title{
The Increasing Importance of Waist-to-Height Ratio to Assess Cardiometabolic Risk: A Plea for Consistent Terminology
}

\author{
Margaret Ashwell $^{* 1,2}$ and Lucy M. Browning ${ }^{1}$ \\ ${ }^{I}$ Ashwell Associates (Europe) Ltd, Ashwell Street, Ashwell, Herts, SG7 5PZ, UK \\ ${ }^{2}$ Oxford Brookes University, Oxford OX3 OBP, UK
}

\begin{abstract}
We have recently performed a systematic review which collated seventy eight cross-sectional and prospective studies exploring waist-to-height ratio and waist circumference or body mass index as predictors of diabetes and cardiovascular disease published in English between 1950 and 2008. This review, which also employed specificity and sensitivity comparisons, indicated that waist-to-height ratio could be a useful global clinical screening tool, with a weighted mean boundary value of 0.5 , supporting the simple public health message "keep your waist circumference to less than half your height". During the collation of evidence, we noticed inconsistency in the site of measurement of waist circumference and also the terminology and abbreviations used to describe 'waist-to-height ratio'. We encourage others to routinely use the waist circumference measurement used most often (that recommended by World Health Organization mid way between the lower rib and the iliac crest) and the terminology 'waist-to-height ratio' abbreviated to WHtR to avoid confusion about this anthropometric index which is growing in popularity for screening for cardiometabolic risk.
\end{abstract}

Keywords: Waist-to-height ratio, waist circumference, abdominal obesity, terminology, body weights and measures.

\section{INTRODUCTION}

The use of waist-to-height ratio (WHtR) for detecting central obesity and its associated health risks was first proposed in the mid 1990s [1-4]. Interest in the practicality and effectiveness of this measure is rising in both adults and children [5-11]. A previous paper [12] systematically reviewed the evidence supporting the use of $\mathrm{WHtR}$, a proxy for abdominal fatness, as a predictor of cardiovascular disease (CVD) and diabetes, and their risk factors. In order to put the relationships into context, the review drew on evidence from prospective and cross-sectional studies, in adults and in children, which reported relationships between $\mathrm{WHtR}$ and either body mass index (BMI) or waist circumference (WC), or both. The analyses showed that WHtR and WC were significant predictors of these cardiometabolic outcomes more often than BMI, with similar odds ratios; sometimes being significant predictors after adjustment for BMI. Receiver operating characteristic curve (ROC) analyses were also summarised to indicate sensitivity and specificity of the potential predictors and to confirm the suitability of WHtR 0.5 as a possible boundary value for WHtR .

During the collation of evidence, we noticed inconsistency in the terminology used to describe 'waist-to-height ratio' and its abbreviated form; also in the site of measurement of waist circumference. This study further investigates those papers cited in the systematic review to collate evidence relating to these two issues.

*Address correspondence to this author at the Ashwell Associates (Europe) Ltd, Ashwell Street, Ashwell, Herts, SG7 5PZ, UK; Tel: +44(0)1462742166; E-mail: margaret@ashwell.uk.com

\section{METHODS}

\section{Search Methods}

The methodology for the systematic review has already been described [12]. We restricted our analysis for this paper to the 78 papers retrieved in the systematic review and those extra 6 papers used in the ROC analysis alone. Full references are given elsewhere [12].

\section{Collation of Terminology Used for Waist-to-Height Ratio}

The title and abstract of each paper was searched by hand to identify the terminology used when waist circumference was divided by height to obtain the anthropometric index of interest and also the abbreviation used throughout the text for that index.

\section{Collation of Site Measurement Methods for Waist Circumference}

The Methods section of each paper was searched by hand to identify the anatomical site used for measuring waist circumference.

\section{RESULTS}

Table 1 shows the overall summary of our analysis.

\section{Collation of Terminology Used for Waist-to-Height Ratio}

The papers retrieved in the systematic review probably represented a conservative range of terminologies for this anthropometric index by the very nature of the search terms used to retrieve the papers in our systematic review. By far 
Table 1. Summary of Analysis

\begin{tabular}{|c|c|c|c|c|c|c|c|}
\hline First author & Refs. & Year & $\begin{array}{l}\text { What full name do they } \\
\text { use for the ratio in text? }\end{array}$ & $\begin{array}{l}\text { What abbreviation } \\
\text { do they use? }\end{array}$ & Code* & Where do they measure waist circumference? & $\operatorname{Code}^{\dagger}$ \\
\hline Hsieh & [1] & 1995 & Waist/height ratio & none & - & umbilicus & 3 \\
\hline Hsieh & [19] & 1995 & Waist/height ratio & none & - & umbilicus & 3 \\
\hline Cox & {$[20]$} & 1997 & $\begin{array}{l}\text { Ratio of Waist } \\
\text { circumference to height }\end{array}$ & WHTR & 1 & $\begin{array}{l}\text { halfway between the lowest rib and the top of the } \\
\text { iliac crest }\end{array}$ & 1 \\
\hline Rissanen & [21] & 1997 & Waist-to-height ratio & WHTR & 1 & $\begin{array}{l}\text { midway between the lateral lower rib margin and } \\
\text { the iliac crest }\end{array}$ & 1 \\
\hline Cox & [22] & 1998 & Waist : height ratio & WHTR & 1 & $\begin{array}{l}\text { midway between the lowest rib and the top of the } \\
\text { hip }\end{array}$ & 1 \\
\hline Sattar & [23] & 1998 & Waist to height ratio & none & - & $\begin{array}{l}\text { midway between the lowest rib margin and the } \\
\text { iliac crest }\end{array}$ & 1 \\
\hline Ko & {$[24]$} & 1999 & Waist-to-height ratio & WTH & 2 & $\begin{array}{l}\text { minimum circumference between the umbilicus } \\
\text { and xiphoid process }\end{array}$ & 4 \\
\hline Patel & {$[25]$} & 1999 & Waist-to-height ratio & none & - & $\begin{array}{l}\text { midpoint between lower costal margin and the } \\
\text { superior iliac crest }\end{array}$ & 1 \\
\hline Thomas & {$[26]$} & 1999 & $\begin{array}{l}\text { Waist circumference -to- } \\
\text { height }\end{array}$ & WHtR & 1 & not stated & - \\
\hline Harris & {$[27]$} & 2000 & Waist-to-height ratio & Waist/height & 2 & umbilicus & 3 \\
\hline Hsieh & {$[28]$} & 2000 & Waist-to-height ratio & $\mathrm{W} / \mathrm{Ht}$ & 2 & umbilical & 3 \\
\hline Savva & {$[29]$} & 2000 & Waist-to-height ratio & WHtR & 1 & umbilicus & 3 \\
\hline Turcato & {$[30]$} & 2000 & Waist-to-height ratio & none & - & $\begin{array}{l}\text { minimum abdominal circumference between the } \\
\text { xiphoid process and the umbilicus. }\end{array}$ & 4 \\
\hline Yasmin & {$[31]$} & 2000 & Waist to height ratio & WHTR & 1 & natural waist & 3 \\
\hline Berber & [32] & 2001 & Waist-to-height ratio & WTH & 2 & $\begin{array}{l}\text { minimum circumference between the umbilicus } \\
\text { and xiphoid process }\end{array}$ & 4 \\
\hline Teixeira & [33] & 2001 & Waist-to-height ratio & WHtR & 1 & narrowest part of the trunk & 2 \\
\hline Hara & {$[34]$} & 2002 & Waist-to-height ratio & $\mathrm{W} / \mathrm{Ht}$ ratio & 2 & umbilicus & 3 \\
\hline Lin & {$[35]$} & 2002 & Waist-to-height ratio & WHtR & 1 & $\begin{array}{l}\text { midway between the inferior margin of the last } \\
\text { rib and the crest of the ileum }\end{array}$ & 1 \\
\hline Lovegrove & {$[36]$} & 2002 & Waist - height ratio & $\mathrm{W} / \mathrm{Ht}$ & 2 & $\begin{array}{c}\text { midway between the lowest rib margin and the } \\
\text { iliac crest }\end{array}$ & 1 \\
\hline Sargeant & {$[37]$} & 2002 & Waist-to-height ratio & WHTR & 1 & between the ribs and iliac crest & 1 \\
\hline Bertsias & [38] & 2003 & Waist-to-height ratio & WHtR & 1 & $\begin{array}{l}\text { middle between } 12 \text { th rib and iliac crest at the } \\
\text { level of umbilicus }\end{array}$ & 1 \\
\hline Ho & [39] & 2003 & Waist to stature ratio & WSR & 3 & $\begin{array}{l}\text { half way between the xiphisternum and the } \\
\text { umbilicus }\end{array}$ & 4 \\
\hline Hsieh & {$[40]$} & 2003 & Waist-to-height ratio & $\mathrm{W} / \mathrm{Ht}$ & 2 & umbilical & 3 \\
\hline Lopatynski & {$[41]$} & 2003 & Waist to height & WHtR & 1 & navel & 3 \\
\hline Sayeed & [42] & 2003 & Waist-to-height ratio & WHtR & 1 & $\begin{array}{l}\text { midway between } 12 \text { th rib and iliac crest on the } \\
\text { mid-axillary line. }\end{array}$ & 1 \\
\hline Tulloch-Reid & [43] & 2003 & Waist-to-height ratio & none & - & umbilicus & 3 \\
\hline Azizi & {$[44]$} & 2004 & Waist-to-height ratio & none & - & point of noticeable waist narrowing & 2 \\
\hline Esmaillzadeh & {$[45]$} & 2004 & Waist-to-height ratio & WHtR & 1 & narrowest level & 2 \\
\hline Mirmiran & [46] & 2004 & Waist-to-height ratio & WHtR & 1 & narrowest level & 2 \\
\hline Wessel & {$[47]$} & 2004 & Waist-height ratio & none & - & umbilicus & 3 \\
\hline Zhang & [48] & 2004 & $\begin{array}{l}\text { Waist-to-standing height } \\
\text { ratio }\end{array}$ & WHtR & 1 & umbilicus & 3 \\
\hline Fuchs & [49] & 2005 & Waist-to-height ratio & none & - & $\begin{array}{l}\text { above the iliac crest and below the lowest rib } \\
\text { margin }\end{array}$ & 1 \\
\hline
\end{tabular}


(Table 1) Contd.....

\begin{tabular}{|c|c|c|c|c|c|c|c|}
\hline First author & Refs. & Year & $\begin{array}{l}\text { What full name do they } \\
\text { use for the ratio in text? }\end{array}$ & $\begin{array}{l}\text { What abbreviation } \\
\text { do they use? }\end{array}$ & Code* & Where do they measure waist circumference? & Code $^{\dagger}$ \\
\hline Hsieh & {$[50]$} & 2005 & Waist-to-height ratio & $\mathrm{W} / \mathrm{Ht}$ & 2 & umbilical & 3 \\
\hline Jeong & {$[51]$} & 2005 & Waist-to-height ratio & WHtR & 1 & $\begin{array}{l}\text { midway between the lower rib margin and the } \\
\text { iliac crest }\end{array}$ & 1 \\
\hline Kahn & {$[52]$} & 2005 & Waist-to-height ratio & WHtR & 1 & $\begin{array}{l}\text { in the horizontal plane at a point marked just } \\
\text { above the right ileum on the mid-axillary line, at } \\
\text { minimal respiration }\end{array}$ & 1 \\
\hline Aekplakorn & {$[53]$} & 2006 & Waist-to-height ratio & WHtR & 1 & horizontal plane at $1 \mathrm{~cm}$ above the navel & 3 \\
\hline Bosy-Westphal & {$[54]$} & 2006 & Waist-to-height ratio & $\mathrm{WC} / \mathrm{ht}$ & 2 & midway between the lowest rib and the iliac crest & 1 \\
\hline Deshmukh & {$[55]$} & 2006 & Waist-height ratio & WHtR & 1 & $\begin{array}{l}\text { halfway between the iliac crest and the costal } \\
\text { margin in the mid-axillary line }\end{array}$ & 1 \\
\hline Esmaillzadeh & {$[56]$} & 2006 & Waist-to-height ratio & WHtR & 1 & narrowest or at end of the lowest rib & 2 \\
\hline Hadaegh & {$[57]$} & 2006 & Waist-to-height ratio & WHtR & 1 & narrowest level and that of hip at maximal level & 2 \\
\hline $\mathrm{Lu}$ & {$[58]$} & 2006 & Waist-to-height ratio & none & - & self reported & - \\
\hline $\begin{array}{l}\text { Mukuddem- } \\
\text { Petersen }\end{array}$ & {$[59]$} & 2006 & Waist-to-height ratio & none & - & $\begin{array}{c}\text { level midway between the lowest rib margin and } \\
\text { the iliac crest }\end{array}$ & 1 \\
\hline Sakurai & {$[60]$} & 2006 & Waist-to-height ratio & none & - & $\begin{array}{c}\text { above the iliac crests and below the lowest rib } \\
\text { margin }\end{array}$ & 1 \\
\hline Aekplakorn & {$[61]$} & 2007 & Waist-to-height ratio & WHtR & 1 & umbilicus & 3 \\
\hline Botton & {$[62]$} & 2007 & Waist-to-height ratio & none & - & between iliac crest and the lower rib & 1 \\
\hline Chehrei & {$[63]$} & 2007 & Waist to height ratio & $\mathrm{W} / \mathrm{Ht}$ & 2 & $\begin{array}{l}\text { halfway between the lower border of ribs and the } \\
\text { iliac crest in a horizontal plane }\end{array}$ & 1 \\
\hline Diaz & {$[64]$} & 2007 & Waist-to-height ratio & WHR & 2 & not stated & - \\
\hline Freedman & [7] & 2007 & Waist-to-height ratio & none & - & $\begin{array}{c}\text { midway between the rib cage and the superior } \\
\text { border of the iliac crest }\end{array}$ & 1 \\
\hline Ghosh & {$[65]$} & 2007 & Waist stature ratio & WSR & 3 & not stated & - \\
\hline Gracey & {$[66]$} & 2007 & Waist-to-height ratio & WTHR & 2 & level of the umbilicus & 3 \\
\hline Mansour & {$[67]$} & 2007 & Waist-to-height ratio & WHtR & 1 & umbilical level from the horizontal plane & 3 \\
\hline Mirzaei & {$[68]$} & 2007 & Waist-to-height ratio & WHR & 2 & navel level & 3 \\
\hline Ruiz & {$[69]$} & 2007 & Waist-to-height ratio & none & - & midway between the lowest rib and the iliac crest & 1 \\
\hline Schneider & [6] & 2007 & Waist to height ratio & WHtR & 1 & midway between the lowest rib and pelvis & 1 \\
\hline Sung & {$[70]$} & 2007 & Waist/height ratio & none & - & $\begin{array}{c}\text { midway between the lowest rib and the superior } \\
\text { border of the iliac crest }\end{array}$ & 1 \\
\hline Wang & {$[71]$} & 2007 & Waist-to-height ratio & WHTR & 1 & measured to $0.1 \mathrm{~cm}$ using standard techniques & - \\
\hline Welborn & {$[72]$} & 2007 & Waist-to-stature ratio & WSR & 3 & $\begin{array}{l}\text { at the narrowest point between ribs and hips after } \\
\text { exhaling }\end{array}$ & 2 \\
\hline $\mathrm{Wu}$ & {$[73]$} & 2007 & Waist to height ratio & WHtR & 1 & full paper not available & - \\
\hline Ajay & {$[74]$} & 2008 & $\begin{array}{l}\text { Waist-circumference-to- } \\
\text { height ratio }\end{array}$ & WC-HR & 2 & standardised protocol & - \\
\hline Bray & {$[75]$} & 2008 & Waist/height ratio & none & - & $\begin{array}{l}\text { midpoint between the highest point of the iliac } \\
\text { crest and the lowest part of the costal margin in } \\
\text { the mid-axillary line }\end{array}$ & 1 \\
\hline Chei & {$[76]$} & 2008 & Waist-to-height ratio & WHtR & 1 & umbilicus & 3 \\
\hline Garnett & {$[77]$} & 2008 & Waist-to-height ratio & WHtR & 1 & $\begin{array}{l}\text { narrowest point between the lower costal border } \\
\text { and the iliac crest }\end{array}$ & 2 \\
\hline Gelber & {$[78]$} & 2008 & Waist-to-height ratio & WHtR & 1 & at level of umbilicus & 3 \\
\hline Kaur & {$[79]$} & 2008 & Waist-to-stature ratio & WSR & 3 & $\begin{array}{l}\text { midpoint between lower end of the rib cage and } \\
\text { iliac crest }\end{array}$ & 1 \\
\hline Khan & {$[80]$} & 2008 & Waist to height ratio & WHTR & 1 & midway between the ribcage and the iliac crest & 1 \\
\hline
\end{tabular}


(Table 1) Contd.....

\begin{tabular}{|c|c|c|c|c|c|c|c|}
\hline First author & Refs. & Year & $\begin{array}{l}\text { What full name do they } \\
\text { use for the ratio in text? }\end{array}$ & $\begin{array}{l}\text { What abbreviation } \\
\text { do they use? }\end{array}$ & Code* & Where do they measure waist circumference? & Code $^{\dagger}$ \\
\hline Kotchen & {$[81]$} & 2008 & Waist/height ratio & none & - & $\begin{array}{l}\text { narrowest point between umbilicus and superior } \\
\text { iliac spine }\end{array}$ & 2 \\
\hline Lee & {$[82]$} & 2008 & Waist-to-height ratio & WHTR & 1 & $\begin{array}{l}\text { midway between the lowest lateral border of the } \\
\text { ribs and the uppermost lateral iliac crest }\end{array}$ & 1 \\
\hline Maffeis & {$[83]$} & 2008 & Waist-to-height ratio & $\mathrm{W} / \mathrm{Hr}$ & 2 & lowest portion of the rib cage and iliac crest & 1 \\
\hline Nyamdorj & {$[85]$} & 2008 & Waist-to-stature ratio & WSR & 3 & $\begin{array}{c}\text { at the midpoint between the lower margin of the } \\
\text { ribs and the iliac crest }\end{array}$ & 1 \\
\hline Paniagua & {$[86]$} & 2008 & Waist-height ratio & WHtR & 1 & $\begin{array}{l}\text { midway between the inferior margin of the last } \\
\text { rib and the iliac crest at the end of expiration }\end{array}$ & 1 \\
\hline Pischon & {$[87]$} & 2008 & Waist-to-height ratio & none & - & $\begin{array}{l}\text { either at the narrowest circumference of the torso } \\
\text { or at the midpoint between the lower ribs and the } \\
\text { iliac crest. }\end{array}$ & 1 \\
\hline Tseng & {$[89]$} & 2008 & Waist-to-height ratio & WHeiR & 2 & $\begin{array}{l}\text { midway between the inferior margin of the last } \\
\text { rib and the crest of the ileum in a horizontal plane }\end{array}$ & 1 \\
\hline Can & {$[90]$} & 2009 & Waist : height ratio & WHtR & 1 & $\begin{array}{l}\text { midpoint between the last rib and the superior } \\
\text { iliac crest during mild expiration }\end{array}$ & 1 \\
\hline Freedman & {$[91]$} & 2009 & Waist/height ratio & WHtR & 1 & $\begin{array}{c}\text { midway between the rib cage and the superior } \\
\text { border of the iliac crest }\end{array}$ & 1 \\
\hline $\mathrm{He}$ & {$[92]$} & 2009 & Waist : height ratio & WHtR & 1 & $\begin{array}{c}\text { halfway between the costal border and the iliac } \\
\text { crest }\end{array}$ & 1 \\
\hline Mackay & {$[93]$} & 2009 & $\begin{array}{l}\text { Waist-height ratio and } \\
\text { Waist-to-height ratio }\end{array}$ & WHtR & 1 & following standardized protocol & - \\
\hline Maher & {$[94]$} & 2009 & Waist/height ratio & WHTR & 1 & midway between the lowest rib and the iliac crest & 1 \\
\hline
\end{tabular}

*Terminology of abbreviation was categorised into 3 groups as described in Table 2 . $\dagger$ Anatomical measurement site was categorised into 4 groups as described in Table $\mathbf{3}$.

Ref: reference.

the majority of papers (90\%) used 'waist-to-height ratio' with just minor changes in the exact terminology (e.g. waist/ height ratio or waist circumference to height). Only 6 papers used waist to stature ratio. As far as abbreviations were concerned, even those authors who used the most popular terminology, waist-to-height ratio, used several different abbreviated forms. The terminology for abbreviations fell broadly into 3 groups as shown in Table 2. The most consistently used abbreviation was WHtR.

\section{Collation of Site Measurement Methods for Waist Circumference}

The anatomical site for measuring WC was described in many ways in the papers. However, the different anatomical sites fell broadly into four groups across studies as shown in Table 3. The most consistently used site was World Health Organization (WHO) definition [13] of halfway between the lower rib margin and the iliac crest.

\section{DISCUSSION}

This is the first paper to focus on terminology for the 'waist-to-height ratio'. It is timely because of the increasing popularity of this anthropometric index and the number of papers showing that it performs well for screening for cardiometabolic outcomes. When conducting our systematic review we realised that terminology presented a problem and this limited analysis of those papers which were retrieved, even with a conservative selection process, showed diversity among them. One problem is that scientific journals have their preferred editorial styles. We have submitted manuscripts using the terminology 'waist-to-height ratio' and discovered the proofs of the accepted papers use the terminology 'waist: height ratio'. We urge authors to ask journal editors to override their grammatical principles for the sake of scientific consistency. Nevertheless, there seems to be a growing consistency among authors and we strongly urge others to use the waist-to-height ratio and to abbreviate this term to WHtR. This will help literature searches to be 
Table 2. Summary of Terminology Abbreviation for Waist-to-Height Ratio

\begin{tabular}{|c|c|c|c|}
\hline $\begin{array}{c}\text { Code for } \\
\text { abbreviation }\end{array}$ & Terminology abbreviation group & $\begin{array}{c}\text { Number of } \\
\text { papers }\end{array}$ & $\begin{array}{c}\text { \% Papers where } \\
\text { abbreviation used }\end{array}$ \\
\hline \hline 1 & Using the terms waist and height and using W and Ht as the abbreviations for them to & 38 & 63 \\
produce either WHtR or WHTR & 16 & 27 \\
\hline 2 & $\begin{array}{c}\text { Using the terms waist and height but using different abbreviations for them such as } \\
\text { WTH, WTHR, W/height, WHr, WHR, W/Ht, WHeiR, WC-HR and WC/Ht }\end{array}$ & 6 & 10 \\
\hline 3 & Using terms such as stature instead of height & 23 & - \\
\hline- & No abbreviation used & & 23 \\
\hline
\end{tabular}

Abbreviations: W: waist; Ht: height; WHtR, WHTR, WTH, WTHR, W/height, WHr, WHR, W/Ht, WHeiR, WC-HR or WC/Ht: waist-to-height ratio.

Table 3. Summary of Anatomical Site Measurement of Waist Circumference

\begin{tabular}{|c|c|c|c|}
\hline $\begin{array}{c}\text { Code for } \\
\text { measurement site }\end{array}$ & Measurement site & $\begin{array}{c}\text { Number of } \\
\text { papers }\end{array}$ & $\begin{array}{c}\text { \% Papers where } \\
\text { measurement site used }\end{array}$ \\
\hline \hline 1 & Using the WHO definition of halfway between the lower rib margin and the iliac crest & 37 & 9 \\
\hline 2 & The minimum WC & 50 & 24 \\
\hline 3 & WC at or 1cm from the umbilicus & 4 & 32 \\
\hline 4 & WC at the midpoint between the xiphoid process and the umbilicus & 8 & - \\
\hline- & Not stated & 5 \\
\hline
\end{tabular}

Abbreviations: WHO: World Health Organization; WC: waist circumference.

comprehensive. It will also help with the acceptance and promotion of the ratio in public health circles.

A good example of this terminology problem has only recently come to our notice. Parikh and colleagues have advocated their 'index of central obesity' [14,15] and they have defined this as a ratio of waist circumference and height. Unfortunately, our standard literature search did not retrieve these papers, even though they present some valuable thoughts about the global potential of waist-toheight ratio.

We are not the first to analyse the diversity of sites for measuring waist circumference. This has been done in a systematic review by others [16] who have concluded that WC measurement protocol has no substantial influence on the association between $\mathrm{WC}$, all-cause and CVD mortality, $\mathrm{CVD}$ and diabetes. The most common WC protocol in their systematic review was the midpoint between the iliac crest and lower margin of rib cage. Our analysis reached the same conclusion. We therefore reiterate the plea by these authors and others [17] for the scientific community to adopt a consistent measurement site and that proposed by WHO seems a sensible choice for conformity [13].

All the scientific papers in our study reported values of waist-to-height ratio as a proportion of 1 , e.g. 0.5 . We have noticed a tendency for public health websites to promote, say, a healthy waist-to-height ratio as $50 \%$. Maybe this is quite a good idea for health promotion and it corresponds nicely to the simple message "Keep your waist circumference to less than half your height". Together with the consumer friendly Shape chart [18] which puts WHtR 0.5 as an important boundary value for risk, it provides the basis for a simple public health campaign.

\section{CONFLICT OF INTEREST}

The author devised and copyrighted the Ashwell ${ }^{\circledR}$ Shape Chart (based on WHtR) which is distributed to health professionals on a non profit making basis.

\section{ACKNOWLEDGEMENTS}

We thank Mrs. Anne Hancock for secretarial assistance.

\section{REFERENCES}

[1] Hsieh SD, Yoshinaga H. Abdominal fat distribution and coronary heart disease risk factors in men-waist/height ratio as a simple and useful predictor. Int J Obes Relat Metab Disord 1995; 19: 585-9.

[2] Hsieh SD, Yoshinaga $\mathrm{H}$. Waist/height ratio as a simple and useful predictor of coronary heart disease risk factors in women. Intern Med 1995; 34: 1147-52.

[3] Lee JS, Aoki K, Kawakubo K, Gunji A. A study on indices of body fat distribution for screening for obesity. Sangyo Eiseigaku Zasshi 1995; 37: 9-18.

[4] Ashwell M, Lejeune S, McPherson K. Ratio of waist circumference to height may be better indicator of need for weight management. BMJ 1996; 312: 377.

[5] Ashwell M, Hsieh SD. Six reasons why the waist-to-height ratio is a rapid and effective global indicator for health risks of obesity and how its use could simplify the international public health message on obesity. Int J Food Sci Nutr 2005; 56: 303-7.

[6] Schneider HJ, Glaesmer H, Klotsche J, et al. Accuracy of anthropometric indicators of obesity to predict cardiovascular risk. J Clin Endocrinol Metab 2007; 92: 589-94.

[7] Freedman DS, Kahn HS, Mei Z, et al. Relation of body mass index and waist-to-height ratio to cardiovascular disease risk factors in children and adolescents: the Bogalusa Heart Study. Am J Clin Nutr 2007; 86: 33-40.

[8] Goulding A, Taylor RW, Grant AM, Parnell WR, Wilson NC, Williams SM. Waist-to-height ratios in relation to BMI z-scores in three ethnic groups from a representative sample of New Zealand children aged 5-14 years. Int J Obes (Lond) 2010; 34: 1188-90. 
[9] Nambiar S, Truby H, Abbott RA, Davies PS. Validating the waistheight ratio and developing centiles for use amongst children and adolescents. Acta Paediatr 2009; 98: 148-52.

[10] Hsieh SD, Ashwell M, Muto T, Tsuji H, Arase Y, Murase T. Urgency of reassessment of role of obesity indices for metabolic risks. Metabolism 2010; 59: 834-40.

[11] Ashwell M, Gibson S. Waist to height ratio is a simple and effective obesity screening tool for cardiovascular risk factors: Analysis of data from the British National Diet And Nutrition Survey of adults aged 19-64 years. Obes Facts 2009; 2: 97-103.

[12] Browning LM, Hsieh SD, Ashwell M. A systematic review of waist-to-height ratio as a screening tool for the prediction of cardiovascular disease and diabetes: 0.5 could be a suitable global boundary value. Nutr Res Rev 2010; 23: 247-69.

[13] World Health Organization. Obesity. Preventing and managing the global epidemic. Report of a WHO Consultation on obesity, Geneva 3-5 June 1997. Geneva: World Health Organization 1998.

[14] Parikh RM, Joshi SR, Menon PS, Shah NS. Index of central obesity - A novel parameter. Med Hypotheses 2007; 68: 1272-5.

[15] Parikh RM, Joshi SR, Pandia K. Index of central obesity is better than waist circumference in defining metabolic syndrome. Metab Syndr Relat Disord 2009; 7: 525-7.

[16] Ross R, Berentzen T, Bradshaw AJ, et al. Does the relationship between waist circumference, morbidity and mortality depend on measurement protocol for waist circumference? Obes Rev 2008; 9: 312-25.

[17] Gaglione MM. Obesity and risk of death. N Engl J Med 2009; 360 : 1042; author reply 3-4.

[18] Ashwell M. Charts based on body mass index and waist-to-height ratio to assess the health risks of obesity: a review. Open Obes J 2011.

[19] Hsieh SD, Yoshinaga H. Is there any difference in coronary heart disease risk factors and prevalence of fatty liver in subjects with normal body mass index having different physiques? Tohoku J Exp Med 1995; 177: 223-31

[20] Cox BD, Whichelow MJ, Ashwell M, Prevost AT, Lejeune SR. Association of anthropometric indices with elevated blood pressure in British adults. Int J Obes Relat Metab Disord 1997; 21: 674-80.

[21] Rissanen P, Hamalainen P, Vanninen E, Tenhunen-Eskelinen M, Uusitupa M. Relationship of metabolic variables to abdominal adiposity measured by different anthropometric measurements and dual-energy X-ray absorptiometry in obese middle-aged women. Int J Obes Relat Metab Disord 1997; 21: 367-71.

[22] Cox BD, Whichelow MJ, Prevost AT. The development of cardiovascular disease in relation to anthropometric indices and hypertension in British adults. Int J Obes Relat Metab Disord 1998; 22: 966-73.

[23] Sattar N, Tan CE, Han TS, et al. Associations of indices of adiposity with atherogenic lipoprotein subfractions. Int $\mathrm{J}$ Obes Relat Metab Disord 1998; 22: 432-9.

[24] Ko GT, Chan JC, Cockram CS, Woo J. Prediction of hypertension, diabetes, dyslipidaemia or albuminuria using simple anthropometric indexes in Hong Kong Chinese. Int J Obes Relat Metab Disord 1999; 23: 1136-42.

[25] Patel S, Unwin N, Bhopal R, et al. A comparison of proxy measures of abdominal obesity in Chinese, European and South Asian adults. Diabet Med 1999; 16: 853-60.

[26] Thomas GN, Young RP, Tomlinson B, et al. A sibling-pair analysis of fasting lipids and anthropometric measurements and their relationship to hypertension. Clin Exp Hypertens 1999; 21: 116176.

[27] Harris MM, Stevens J, Thomas N, Schreiner P, Folsom AR. Associations of fat distribution and obesity with hypertension in a bi-ethnic population: the ARIC study. Atherosclerosis Risk in Communities Study. Obes Res 2000; 8: 516-24.

[28] Hsieh SD, Yoshinaga H, Muto T, Sakurai Y, Kosaka K. Health risks among Japanese men with moderate body mass index. Int J Obes Relat Metab Disord 2000; 24: 358-62.

[29] Savva SC, Tornaritis M, Savva ME, et al. Waist circumference and waist-to-height ratio are better predictors of cardiovascular disease risk factors in children than body mass index. Int $\mathrm{J}$ Obes Relat Metab Disord 2000; 24: 1453-8.

[30] Turcato E, Bosello O, Di Francesco V, et al. Waist circumference and abdominal sagittal diameter as surrogates of body fat distribution in the elderly: their relation with cardiovascular risk factors. Int J Obes Relat Metab Disord 2000; 24: 1005-10.
[31] Yasmin, Mascie-Taylor CG. Adiposity indices and their relationship with some risk factors of coronary heart disease in middle-aged Cambridge men and women. Ann Hum Biol 2000; 27: 239-48.

[32] Berber A, Gomez-Santos R, Fanghanel G, Sanchez-Reyes L. Anthropometric indexes in the prediction of type 2 diabetes mellitus, hypertension and dyslipidaemia in a Mexican population. Int J Obes Relat Metab Disord 2001; 25: 1794-9.

[33] Teixeira PJ, Sardinha LB, Going SB, Lohman TG. Total and regional fat and serum cardiovascular disease risk factors in lean and obese children and adolescents. Obes Res 2001; 9: 432-42.

[34] Hara M, Saitou E, Iwata F, Okada T, Harada K. Waist-to-height ratio is the best predictor of cardiovascular disease risk factors in Japanese schoolchildren. J Atheroscler Thromb 2002; 9: 127-32.

[35] Lin WY, Lee LT, Chen CY, et al. Optimal cut-off values for obesity: using simple anthropometric indices to predict cardiovascular risk factors in Taiwan. Int J Obes Relat Metab Disord 2002; 26: 1232-8.

[36] Lovegrove JA, Silva KD, Wright JW, Williams CM. Adiposity, insulin and lipid metabolism in post-menopausal women. Int $\mathrm{J}$ Obes Relat Metab Disord 2002; 26: 475-86.

[37] Sargeant LA, Bennett FI, Forrester TE, Cooper RS, Wilks RJ. Predicting incident diabetes in Jamaica: the role of anthropometry. Obes Res 2002; 10: 792-8.

[38] Bertsias G, Mammas I, Linardakis M, Kafatos A. Overweight and obesity in relation to cardiovascular disease risk factors among medical students in Crete, Greece. BMC Public Health 2003; 3: 3.

[39] Ho SY, Lam TH, Janus ED. Waist to stature ratio is more strongly associated with cardiovascular risk factors than other simple anthropometric indices. Ann Epidemiol 2003; 13: 683-91.

[40] Hsieh SD, Yoshinaga H, Muto T. Waist-to-height ratio, a simple and practical index for assessing central fat distribution and metabolic risk in Japanese men and women. Int J Obes Relat Metab Disord 2003; 27: 610-6.

[41] Lopatynski J, Mardarowicz G, Szczesniak G. A comparative evaluation of waist circumference, waist-to-hip ratio, waist-toheight ratio and body mass index as indicators of impaired glucose tolerance and as risk factors for type-2 diabetes mellitus. Ann Univ Mariae Curie Sklodowska Med 2003; 58: 413-9.

[42] Sayeed MA, Mahtab H, Latif ZA, et al. Waist-to-height ratio is a better obesity index than body mass index and waist-to-hip ratio for predicting diabetes, hypertension and lipidemia. Bangladesh Med Res Counc Bull 2003; 29: 1-10.

[43] Tulloch-Reid MK, Williams DE, Looker HC, Hanson RL, Knowler WC. Do measures of body fat distribution provide information on the risk of type 2 diabetes in addition to measures of general obesity? Comparison of anthropometric predictors of type 2 diabetes in Pima Indians. Diabetes Care 2003; 26: 2556-61.

[44] Azizi F, Esmaillzadeh A, Mirmiran P. Obesity and cardiovascular disease risk factors in Tehran adults: A population-based study. East Mediterr Health J 2004; 10: 887-97.

[45] Esmaillzadeh A, Mirmiran P, Azizi F. Waist-to-hip ratio is a better screening measure for cardiovascular risk factors than other anthropometric indicators in Tehranian adult men. Int J Obes Relat Metab Disord 2004; 28: 1325-32.

[46] Mirmiran P, Esmaillzadeh A, Azizi F. Detection of cardiovascular risk factors by anthropometric measures in Tehranian adults: receiver operating characteristic (ROC) curve analysis. Eur J Clin Nutr 2004; 58: 1110-8.

[47] Wessel TR, Arant CB, Olson MB, et al. Relationship of physical fitness vs body mass index with coronary artery disease and cardiovascular events in women. JAMA 2004; 292: 1179-87.

[48] Zhang X, Shu XO, Gao YT, et al. Anthropometric predictors of coronary heart disease in Chinese women. Int J Obes Relat Metab Disord 2004; 28: 734-40.

[49] Fuchs FD, Gus M, Moreira LB, et al. Anthropometric indices and the incidence of hypertension: a comparative analysis. Obes Res 2005; 13: 1515-7.

[50] Hsieh SD, Muto T. The superiority of waist-to-height ratio as an anthropometric index to evaluate clustering of coronary risk factors among non-obese men and women. Prev Med 2005; 40: 216-20.

[51] Jeong SK, Seo MW, Kim YH, Kweon SS, Nam HS. Does waist indicate dyslipidemia better than BMI in Korean adult population? J Korean Med Sci 2005; 20: 7-12. 
[52] Kahn HS, Imperatore G, Cheng YJ. A population-based comparison of BMI percentiles and waist-to-height ratio for identifying cardiovascular risk in youth. J Pediatr 2005; 146: 482-8.

[53] Aekplakorn W, Kosulwat V, Suriyawongpaisal P. Obesity indices and cardiovascular risk factors in Thai adults. Int J Obes (Lond) 2006; 30: 1782-90.

[54] Bosy-Westphal A, Geisler C, Onur S, et al. Value of body fat mass vs anthropometric obesity indices in the assessment of metabolic risk factors. Int J Obes (Lond) 2006; 30: 475-83.

[55] Deshmukh PR, Gupta SS, Dongre AR, et al. Relationship of anthropometric indicators with blood pressure levels in rural Wardha. Indian J Med Res 2006; 123: 657-64.

[56] Esmaillzadeh A, Mirmiran P, Azizi F. Comparative evaluation of anthropometric measures to predict cardiovascular risk factors in Tehranian adult women. Public Health Nutr 2006; 9: 61-9.

[57] Hadaegh F, Zabetian A, Harati H, Azizi F. Waist/height ratio as a better predictor of type 2 diabetes compared to body mass index in Tehranian adult men--a 3.6-year prospective study. Exp Clin Endocrinol Diabetes 2006; 114: 310-5.

[58] Lu M, Ye W, Adami HO, Weiderpass E. Prospective study of body size and risk for stroke amongst women below age 60. J Intern Med 2006; 260: 442-50.

[59] Mukuddem-Petersen J, Snijder MB, van Dam RM, et al. Sagittal abdominal diameter: no advantage compared with other anthropometric measures as a correlate of components of the metabolic syndrome in elderly from the Hoorn Study. Am J Clin Nutr 2006; 84: 995-1002.

[60] Sakurai M, Miura K, Takamura T, et al. Gender differences in the association between anthropometric indices of obesity and blood pressure in Japanese. Hypertens Res 2006; 29: 75-80.

[61] Aekplakorn W, Pakpeankitwatana V, Lee CM, et al. Abdominal obesity and coronary heart disease in Thai men. Obesity (Silver Spring) 2007; 15: 1036-42.

[62] Botton J, Heude B, Kettaneh A, et al. Cardiovascular risk factor levels and their relationships with overweight and fat distribution in children: the Fleurbaix Laventie Ville Sante II study. Metabolism 2007; 56: 614-22.

[63] Chehrei A, Sadrnia S, Keshteli AH, Daneshmand MA, Rezaei J. Correlation of dyslipidemia with waist to height ratio, waist circumference, and body mass index in Iranian adults. Asia Pac J Clin Nutr 2007; 16: 248-53.

[64] Diaz VA, Mainous AG, 3rd, Baker R, Carnemolla M, Majeed A. How does ethnicity affect the association between obesity and diabetes? Diabet Med 2007; 24: 1199-204.

[65] Ghosh JR, Bandyopadhyay AR. Comparative evaluation of obesity measures: relationship with blood pressures and hypertension. Singapore Med J 2007; 48: 232-5.

[66] Gracey M, Burke V, Martin DD, Johnston RJ, Jones T, Davis EA. Assessment of risks of "lifestyle" diseases including cardiovascular disease and type 2 diabetes by anthropometry in remote Australian Aborigines. Asia Pac J Clin Nutr 2007; 16: 688-97.

[67] Mansour AA, Al-Jazairi MI. Cut-off values for anthropometric variables that confer increased risk of type 2 diabetes mellitus and hypertension in Iraq. Arch Med Res 2007; 38: 253-8.

[68] Mirzaei M, Taylor R, Morrell S, Leeder SR. Predictors of blood pressure in a cohort of school-aged children. Eur J Cardiovasc Prev Rehabil 2007; 14: 624-9.

[69] Ruiz JR, Ortega FB, Loit HM, Veidebaum T, Sjostrom M. Body fat is associated with blood pressure in school-aged girls with low cardiorespiratory fitness: the European Youth Heart Study. J Hypertens 2007; 25: 2027-34.

[70] Sung RY, Yu CC, Choi KC, et al. Waist circumference and body mass index in Chinese children: cutoff values for predicting cardiovascular risk factors. Int J Obes (Lond) 2007; 31: 550-8.

[71] Wang Z, Rowley K, Piers L, O'Dea K. Anthropometric indices and their relationship with diabetes, hypertension and dyslipidemia in Australian Aboriginal people and Torres Strait Islanders. Eur J Cardiovasc Prev Rehabil 2007; 14: 172-8.

[72] Welborn TA, Dhaliwal SS. Preferred clinical measures of central obesity for predicting mortality. Eur J Clin Nutr 2007; 61: 1373-9.

[73] Wu HY, Chen LL, Zheng J, Liao YF, Zhou M. Simple anthropometric indices in relation to cardiovascular risk factors in Chinese type 2 diabetic patients. Chin J Physiol 2007; 50: 135-42.

[74] Ajay VS, Prabhakaran D, Jeemon P, et al. Prevalence and determinants of diabetes mellitus in the Indian industrial population. Diabet Med 2008; 25: 1187-94.
[75] Bray GA, Jablonski KA, Fujimoto WY, et al. Relation of central adiposity and body mass index to the development of diabetes in the Diabetes Prevention Program. Am J Clin Nutr 2008; 87: 12128.

[76] Chei CL, Iso H, Yamagishi K, et al. Body fat distribution and the risk of hypertension and diabetes among Japanese men and women. Hypertens Res 2008; 31: 851-7.

[77] Garnett SP, Baur LA, Cowell CT. Waist-to-height ratio: a simple option for determining excess central adiposity in young people. Int J Obes (Lond) 2008; 32: 1028-30.

[78] Gelber RP, Gaziano JM, Orav EJ, Manson JE, Buring JE, Kurth T. Measures of obesity and cardiovascular risk among men and women. J Am Coll Cardiol 2008; 52: 605-15.

[79] Kaur P, Radhakrishnan E, Sankarasubbaiyan S, et al. A comparison of anthropometric indices for predicting hypertension and type 2 diabetes in a male industrial population of Chennai, South India. Ethn Dis 2008; 18: 31-6.

[80] Khan A, Haq FU, Pervez MB, et al. Anthropometric correlates of blood pressure in normotensive Pakistani subjects. Int J Cardiol 2008; 124: 259-62.

[81] Kotchen TA, Grim CE, Kotchen JM, et al. Altered relationship of blood pressure to adiposity in hypertension. Am J Hypertens 2008; 21: 284-9.

[82] Lee K, Song YM, Sung J. Which obesity indicators are better predictors of metabolic risk?: healthy twin study. Obesity (Silver Spring) 2008; 16: 834-40.

[83] Maffeis C, Banzato C, Talamini G. Waist-to-height ratio, a useful index to identify high metabolic risk in overweight children. $\mathrm{J}$ Pediatr 2008; 152: 207-13.

[84] Manios Y, Kourlaba G, Kafatos A, Cook TL, Spyridaki A, Fragiadakis GA. Associations of several anthropometric indices with insulin resistance in children: The Children Study. Acta Paediatr 2008; 97: 494-9.

[85] Nyamdorj R, Qiao Q, Soderberg S, et al. Comparison of body mass index with waist circumference, waist-to-hip ratio, and waist-tostature ratio as a predictor of hypertension incidence in Mauritius. J Hypertens 2008; 26: 866-70.

[86] Paniagua L, Lohsoonthorn V, Lertmaharit S, Jiamjarasrangsi W, Williams MA. Comparison of waist circumference, body mass index, percent body fat and other measure of adiposity in identifying cardiovascular disease risks among Thai adults. Obes Res Clin Pract 2008; 2: 215-23.

[87] Pischon T, Boeing H, Hoffmann K, et al. General and abdominal adiposity and risk of death in Europe. N Engl J Med 2008; 359: 2105-20.

[88] Shimajiri T, Imagawa M, Kokawa M, et al. Revised optimal cut-off point of waist circumference for the diagnosis of metabolic syndrome in Japanese women and the influence of height. J Atheroscler Thromb 2008; 15: 94-9.

[89] Tseng $\mathrm{CH}$. Waist-to-height ratio and coronary artery disease in Taiwanese type 2 diabetic patients. Obesity (Silver Spring) 2008; 16: 2754-9.

[90] Can AS, Bersot TP, Gonen M. Anthropometric indices and their relationship with cardiometabolic risk factors in a sample of Turkish adults. Public Health Nutr 2009; 12: 538-46.

[91] Freedman DS, Dietz WH, Srinivasan SR, Berenson GS. Risk factors and adult body mass index among overweight children: the Bogalusa Heart Study. Pediatrics 2009; 123: 750-7.

[92] He Y, Zhai F, Ma G, et al. Abdominal obesity and the prevalence of diabetes and intermediate hyperglycaemia in Chinese adults. Public Health Nutr 2009; 12: 1078-84.

[93] MacKay MF, Haffner SM, Wagenknecht LE, D'Agostino RB, Jr., Hanley AJ. Prediction of type 2 diabetes using alternate anthropometric measures in a multi-ethnic cohort: the insulin resistance atherosclerosis study. Diabetes Care 2009; 32: 956-8.

[94] Maher V, O'Dowd M, Carey M, et al. Association of central obesity with early carotid intima-media thickening is independent of that from other risk factors. Int J Obes (Lond) 2009; 33: 136-43.

[95] Nyamdorj R, Qiao Q, Soderberg S, et al. BMI compared with central obesity indicators as a predictor of diabetes incidence in Mauritius. Obesity (Silver Spring) 2009; 17: 342-8.

[96] Page JH, Rexrode KM, Hu F, Albert CM, Chae CU, Manson JE. Waist-height ratio as a predictor of coronary heart disease among women. Epidemiology 2009; 20: 361-6.

[97] Panagiotakos DB, Chrysohoou C, Pitsavos C, et al. Hierarchical analysis of anthropometric indices in the prediction of 5-year 
incidence of hypertension in apparently healthy adults: the ATTICA study. Atherosclerosis 2009; 206: 314-20.
[98] Zhang X, Shu XO, Gao YT, Yang G, Li H, Zheng W. General and abdominal adiposity and risk of stroke in Chinese women. Stroke 2009; 40: 1098-104.

Received: August 18, 2010

(C) Ashwell and Browning; Licensee Bentham Open.

This is an open access article licensed under the terms of the Creative Commons Attribution Non-Commercial License (http: //creativecommons.org/licenses/by$\mathrm{nc} / 3.0 /$ ), which permits unrestricted, non-commercial use, distribution and reproduction in any medium, provided the work is properly cited. 